\title{
Microbe-Mediated Germination of Ascospores of Monosporascus cannonballus
}

\author{
M. E. Stanghellini, D. H. Kim, and M. Waugh
}

Department of Plant Pathology, University of California, Riverside 92521.

Accepted for publication 15 November 1999.

\begin{abstract}
Stanghellini, M. E., Kim, D. H., and Waugh, M. 2000. Microbe-mediated germination of ascospores of Monosporascus cannonballus. Phytopathology 90:243-247.

Ascospores of Monosporascus cannonballus germinated readily in the rhizosphere of cantaloupe plants growing in field soil. However, little or no germination occurred in the rhizosphere of melon plants growing in field soil that was autoclaved prior to infestation with ascospores. The latter data suggested that root exudates alone do not stimulate ascospore germination and that the soil microflora may be involved in the induction of ascospore germination. Amending field soil with streptomycin (which inhibits gram-negative microorganisms) did not suppress ascospore germination in the rhizosphere of cantaloupe plants. However, amending the
\end{abstract}

ABSTRACT soil with penicillin (which inhibits gram-positive microorganisms) did suppress ascospore germination. Pentachloronitrobenzene (PCNB), which inhibits the gram-positive actinomycetes but does not inhibit gram-positive or gram-negative bacteria, also suppressed ascospore germination. These results suggest that actinomycetes, either directly or indirectly, are involved in the induction of ascospore germination in field soil in the presence of exudates from cantaloupe roots. Optimum germination occurred at temperatures ranging from 25 to $35^{\circ} \mathrm{C}$, and data indicate that a high percentage ( $\geq 72 \%$ ) of the ascospore population within $500 \mu \mathrm{m}$ of a root are capable of germination and subsequent penetration of cantaloupe roots.

Additional keywords: inoculum efficiency, rhizosphere width, soil temperature.
Monosporascus cannonballus Pollack \& Uecker, a root-infecting ascomycete, has been identified as the causal agent of a destructive disease of cantaloupe (Cucumis melo L.) $(6,8)$. Perithecia, containing single-spored asci, are produced in the cortex of colonized roots. No other spore stage is known to be produced by this pathogen; therefore, ascospores are considered to function as both the primary survival and source of inoculum for this soilborne pathogen. However, neither culturally produced ascospores nor naturally occurring ascospores recovered from soil germinate in axenic culture $(6,8)$. Lack of germination has hindered studies of the role of ascospores in the ecology and epidemiology of this pathogen.

Recently, we showed that ascospores of $M$. cannonballus, either recovered from naturally infested soil or culturally produced, are viable and germinate in the rhizosphere of cantaloupe plants growing in field soil (8). However, subsequent studies (M. E. Stanghellini and D. H. Kim, unpublished data) showed that little or no ascospore germination occurred in the rhizosphere of cantaloupe plants if the field soil was autoclaved prior to infestation with either naturally or culturally produced ascospores. The latter observation suggested that root exudates alone do not stimulate ascospore germination and that the soil microflora may be involved, either directly or indirectly, in the induction of ascospore germination.

The objectives of this investigation were to provide quantitative data on the influence of the soil microflora and soil temperature on the percentage and rate of germination of ascospores of $M$. cannonballus in the rhizosphere of cantaloupe roots.

\section{MATERIALS AND METHODS}

Soil infestation procedures. Soil ( $2 \mathrm{~kg}$ of fine sandy loam, $0.37 \%$ total carbon content measured by dry combustion) was collected

Corresponding author: M. E. Stanghellini;

E-mail address: mstang@ucrac1.ucr.edu

Publication no. P-2000-0118-01R

(C) 2000 The American Phytopathological Society from a commercial melon field that had a history of vine decline, transported to the laboratory, passed through a 2-mm mesh screen, and allowed to air-dry for $72 \mathrm{~h}$. One-fourth of the volume of soil was autoclaved for $30 \mathrm{~min}$, allowed to air dry for $24 \mathrm{~h}$, and reautoclaved for $30 \mathrm{~min}$. The autoclaved and nonautoclaved portions were then infested artificially with ascospores that were obtained from 1-month-old V8 agar cultures of M. cannonballus (BH3-19). Artificially infested soils were air-dried for $48 \mathrm{~h}$ and stored in plastic bags at $24^{\circ} \mathrm{C}$ until used. A quantitative extraction technique (9) was used to estimate ascospore population densities in the soil prior to and after artificial infestation. Ascospore population densities were estimated (mean \pm standard error [SE] of 5, 10-g soil subsamples) at $2.5 \pm 2.0$ ascospores per $g$ of soil prior to artificial infestation and 4,640 \pm 650 ascospores per $g$ of soil after artificial infestation.

Ascospore germination assessment. Subsamples (7 g) of artificially infested soil (autoclaved and nonautoclaved) were dispensed into polypropylene centrifuge tubes $(8 \mathrm{~cm}$ long and $1.7 \mathrm{~cm}$ diameter). A total of five water drainage holes (1 $\mathrm{mm}$ in diameter) were drilled through the bottom of each tube prior to filling with soil. Tubes were irrigated with sterile distilled water (SDW) until drainage occurred. A 2-day-old cantaloupe (cv. Caravelle) seedling (pregerminated on water agar, radical length of $1 \mathrm{~mm}$ ) was transplanted into each tube. Seeded tubes were placed in test-tube racks, transferred to growth chambers (12-h photoperiod), and incubated at $15,20,25,30,35$, and $40^{\circ} \mathrm{C}$ for time periods that, depending on the particular experiment, ranged from 1 to 21 days. Subsequent to transplant, all tubes were irrigated on alternate days. At the termination of each experiment, the seedlings were removed from the tubes, and the root system of each seedling was gently washed in tap water and placed in petri dishes containing $\approx 15 \mathrm{ml}$ of SDW. The root system of each seedling was examined microscopically at 40 to $400 \times$. The number and location of ascospore germlings of $M$. cannonballus attached to the root system of each seedling, as well as the length of germ tubes, was recorded. The length and diameter of the roots per plant per treatment also were recorded. Unless otherwise specified, all treat- 
ments were replicated three times, and all experiments were repeated three times.

Temperature effects on rate of ascospore germination. Melon seedlings were transplanted into artificially infested, nonautoclaved field soil and incubated at $15,20,25,30,35$, and $40^{\circ} \mathrm{C}$. At daily intervals, the number of ascospore germlings attached to the root system of three seedlings per temperature treatment were assessed as described above. Additionally, the mycelial growth rate of the fungus at various incubation temperatures was assessed as follows: a plug (5 mm diameter) was excised from a 10-day-old V8 agar culture of the fungus and placed in petri dishes containing solidified $10 \% \mathrm{~V} 8$ agar. At 24 -h intervals, the radial growth of the developing colony was marked and the rate of growth at various temperatures was estimated from three consecutive measurements per incubation temperature. There were three replications per temperature, and the experiment was repeated once.

Ascospore germination in autoclaved versus nonautoclaved soil. Melon seedlings were transplanted into artificially infested autoclaved and nonautoclaved soil. The number of ascospore germlings attached to the root system of three seedlings per soil treatment were assessed, as described above, after 8 days of incubation at $25^{\circ} \mathrm{C}$.

Ascospore germination in antibiotic- and pentachloronitrobenzene-amended soil. Seedlings were transplanted into nonautoclaved field soil and irrigated with SDW containing streptomycin (Sigma-Aldrich, St. Louis) at 1,000 $\mu \mathrm{g} / \mathrm{ml}$, penicillin (Sigma-Aldrich)

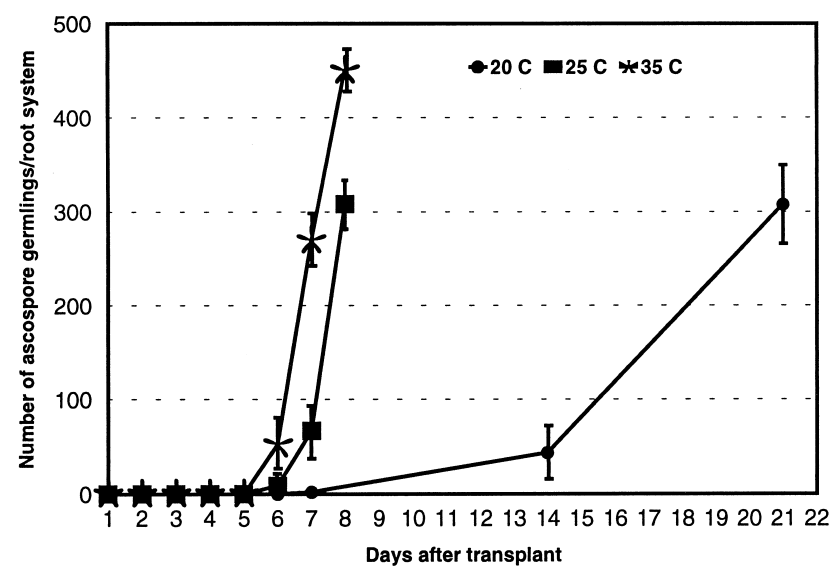

Fig. 1. Effect of temperature and duration of incubation on the number of ascospore germlings attached to the root system of cantaloupe seedlings growing in nonautoclaved field soil artificially infested with ascospores of Monosporascus cannonballus.

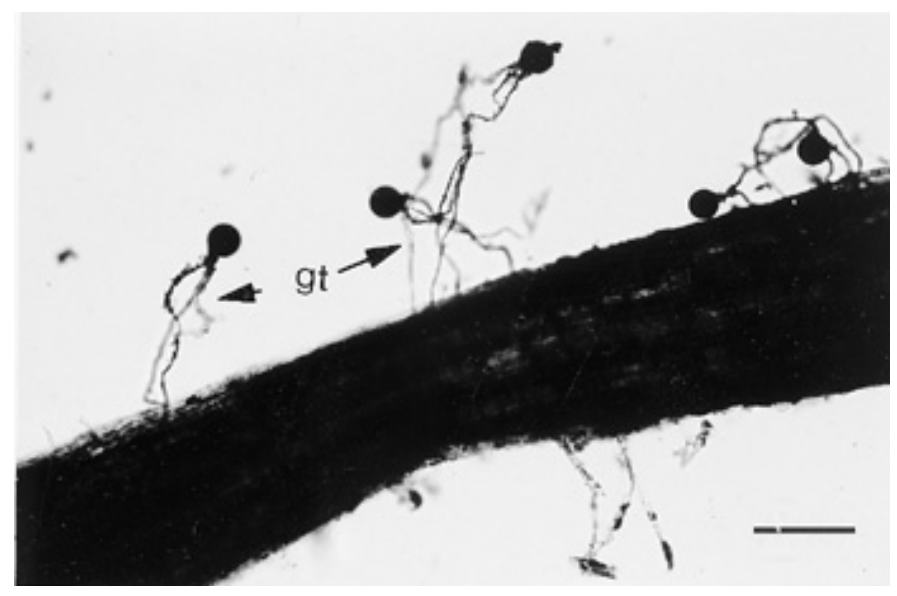

Fig. 2. Five ascospore germlings of Monosporascus cannonballus attached by two or three germ tubes ( $\mathrm{gt}$ ) to a secondary root of a cantaloupe seedling grown in artificially infested soil for 8 days at $25^{\circ} \mathrm{C}$ (bar $\left.=133 \mu \mathrm{m}\right)$. at $1,000 \mu \mathrm{g} / \mathrm{ml}$, or pentachloronitrobenzene (PCNB; Terraclor, Olin) at $100 \mu \mathrm{g} / \mathrm{ml}$. Controls consisted of seedlings irrigated with SDW. Three seedlings per treatment were assessed for ascospore germination after 8 days of incubation at $25^{\circ} \mathrm{C}$. The experiment was repeated three times. Preliminary studies showed that the above chemical amendments had no significant effects on mycelial growth rates of the fungus when the latter was seeded on V8 agar containing the above concentrations of these chemicals.

Ascospore germination. The number of ascospore germlings attached to the root system of seedlings was used to estimate the percentage of the ascospore population that germinated in the rhizosphere of melon seedlings. Estimates of the percentage germination were calculated as follows: first, ascospore population densities in the artificially infested soil were converted from the number of ascospores per weight (gram) of soil to the number of ascospores per volume (cubic millimeters) of soil. The bulk density of the soil used in our study was $1.358 \mathrm{~g} / \mathrm{cm}^{3}$. Second, the volume of soil within various rhizosphere widths adjacent to the surface area of a root of known dimensions (i.e., $2 \pi \mathrm{rh}$ ) was determined. The calculated number of ascospores within a known volume of soil adjacent to the surface area of a root of known dimensions (length and diameter) was then compared to the observed number of ascospore germlings that were attached to a root of the same dimensions and percentage germination estimated.

Statistical analyses. Lack of significant variation, as shown by Bartlett's test of homogeneity, permitted the combining of data from all replications of the same treatment from repeated experiments. Combined data were analyzed by analysis of variance to determine treatment effects, and mean comparisons were made using the least significant difference test.

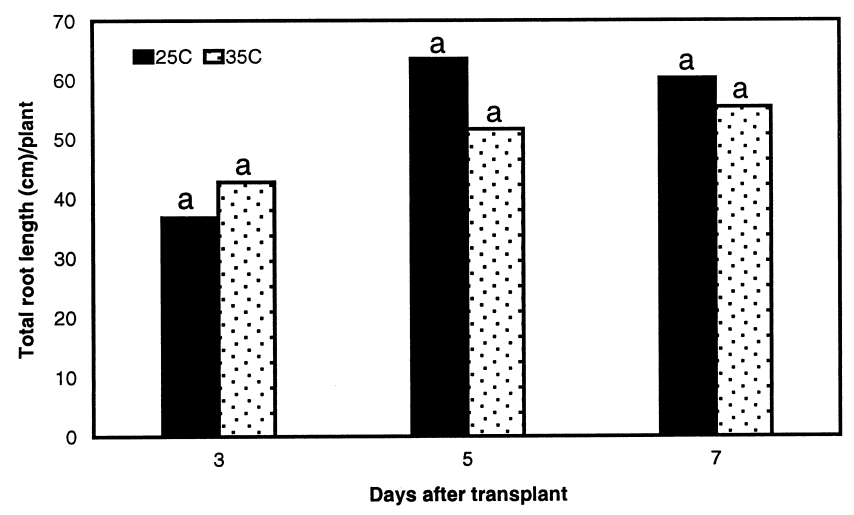

Fig. 3. Effect of temperature on the total root length of cantaloupe seedlings growing in nonautoclaved field soil artificially infested with ascospores of Monosporascus cannonballus. For each time interval, bars with the same letter are not significantly different $(P \leq 0.05)$ according to a least significant difference test. Combined results of three separate experiments, representing a total of nine replications per treatment, are shown.

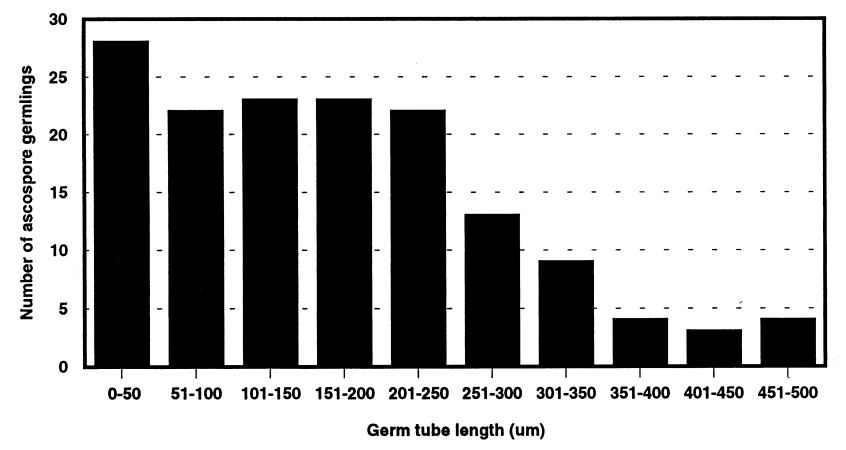

Fig. 4. Distribution of germ tube lengths of 150 ascospore germlings attached to cantaloupe roots after 8 days of incubation at $25^{\circ} \mathrm{C}$. 


\section{RESULTS}

Temperature effects on ascospore germination. Ascospore germlings were first observed attached to roots of melon seedlings six days after transplant, and their numbers increased rapidly to a maximum quantity after eight days of incubation at 25 and $35^{\circ} \mathrm{C}$ (Figs. 1 and 2). The rate of germination and the numbers of germlings attached to roots at $30^{\circ} \mathrm{C}$ was intermediate between that recorded at 25 and $35^{\circ} \mathrm{C}$ (data not presented). The numbers of ascospore germlings attached to the root system of plants incubated at $35^{\circ} \mathrm{C}(454 \pm 24.9)$ were significantly higher (in analysis of variance [ANOVA] $P=0.002)$ than those recorded at $25^{\circ} \mathrm{C}(310 \pm$ 18.8). There were, however, no significant differences $(P=0.548)$ in the total length of the root system of plants incubated at 25 or $35^{\circ} \mathrm{C}$ (Fig. 3). No ascospore germlings were observed on melon roots after 8 days of incubation at $15^{\circ} \mathrm{C}$. At $20^{\circ} \mathrm{C}$, a few ascospore germlings $(\leq 50)$ were observed on melon roots after 7 and 14 days of incubation, but high numbers $(308 \pm 58.5)$ were observed on melon roots when the duration of incubation was extended to 21 days (Fig. 1). Extended incubation periods were not conducted at $15^{\circ} \mathrm{C}$ and melon seedlings did not grow at $40^{\circ} \mathrm{C}$. Most $(\approx 80 \%)$ of the attached ascospore germlings, irrespective of incubation temperature, were located on the oldest portions of the tap root and secondary roots. Microscopic examination showed that the tips of the germ tubes had penetrated the epidermal cells, thus firmly

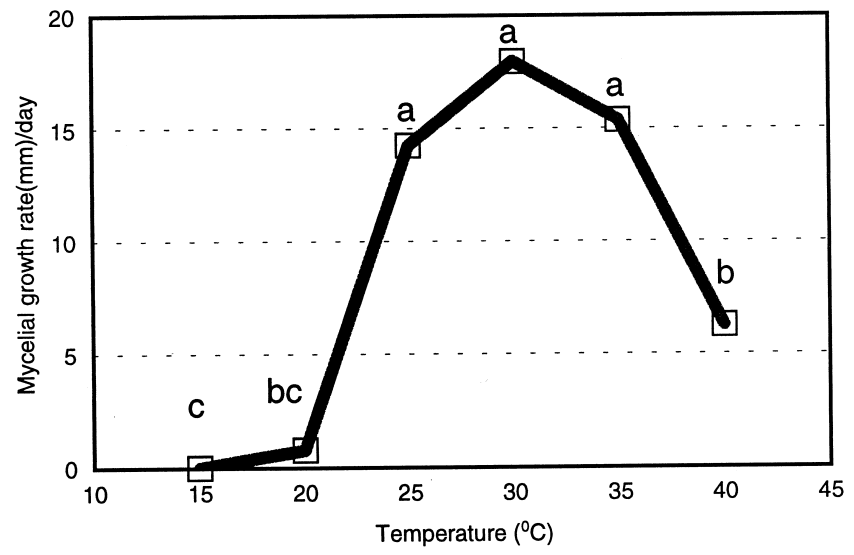

Fig. 5. Effect of temperature on the rate of mycelial growth of Monosporascus cannonballus. For each temperature interval, means with the same letter are not significantly different $(P \leq 0.05)$ according to a least significant difference test. Combined results of two separate experiments, representing a total of six replications per temperature, are shown.

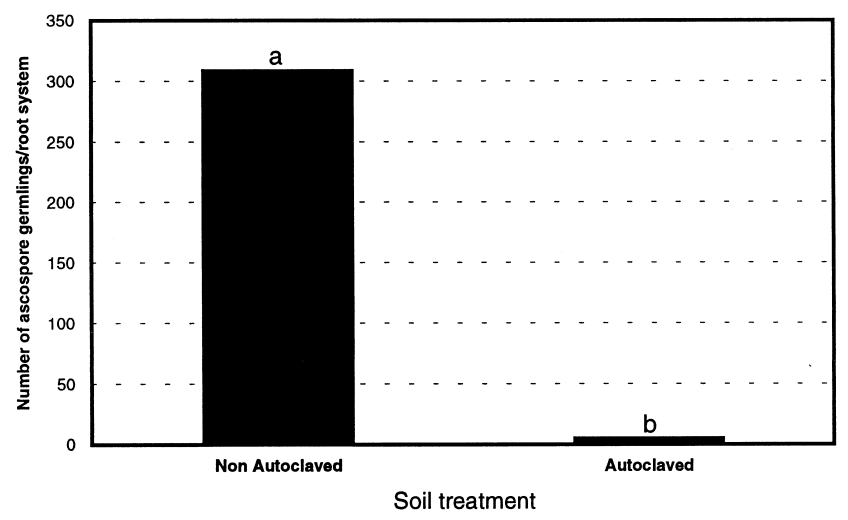

Fig. 6. Comparison of the number of ascospore germlings of Monosporascus cannonballus attached to roots of cantaloupe seedlings growing in artificially infested autoclaved soil and nonautoclaved soil. Bars with the same letter are not significantly different $(P \leq 0.05)$ according to a least significant difference test. Combined results of three separate experiments, representing a total of nine replications per treatment, are shown. anchoring the ascospore germling to the root. Histological studies on host penetration and colonization are in progress. Germ-tube lengths of 150 ascospore germlings (three readings of 50 spores each) that were attached to melon roots after 8 days of incubation at $25^{\circ} \mathrm{C}$ were recorded (Fig. 4). The maximum germ tube length recorded was $500 \mu \mathrm{m}$.

The effect of temperature on the rate of mycelial growth of $M$. cannonballus on V8 agar was examined (Fig. 5). No significant differences (ANOVA, $P=0.0015)$ between mycelial growth rates $(\approx 600 \mu \mathrm{m} / \mathrm{h})$ were detected at incubation temperatures of 25,30 , or $35^{\circ} \mathrm{C}$. Mycelial growth rates at 20 and $40^{\circ} \mathrm{C}$ were significantly lower (ANOVA, $P=0.0015$ ) than at the above three temperature regimes, and no growth occurred at $15^{\circ} \mathrm{C}$.

Ascospore germination in autoclaved versus nonautoclaved soil. The number of ascospore germlings attached to the root system of 8-day-old of melon seedlings at $25^{\circ} \mathrm{C}$ was significantly lower (ANOVA, $P=0.0001$ ) in artificially infested autoclaved soil ( $3 \pm 0.89)$ compared to artificially infested nonautoclaved (control) soil (320 \pm 62.0) (Fig. 6).

Ascospore germination in antibiotic- and PCNB-amended soil. The number of ascospore germlings attached to the root system of 8-day-old melon seedlings at $25^{\circ} \mathrm{C}$ were significantly lower (ANOVA, $P=0.0001)$ in soil amended with either penicillin $(35 \pm 2.4)$ or PCNB $(28 \pm 4.1)$ compared with either unamended (control) soil $(308 \pm 58.5)$ or soil amended with streptomycin (243 \pm 15.0$)$ (Fig. 7).

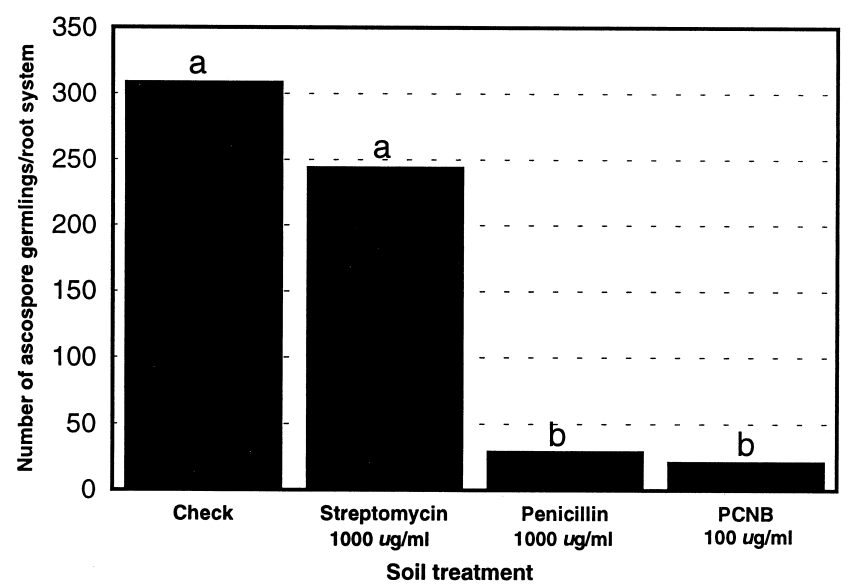

Fig. 7. Number of ascospore germlings of Monosporascus cannonballus attached to roots of cantaloupe seedlings growing in artificially infested soil amended with penicillin, streptomycin, or pentachloronitrobenzene (PCNB). Bars with the same letter are not significantly different $(P \leq 0.05)$ according to a least significant difference test. Combined results of three separate experiments, representing a total of nine replications per treatment, are shown.

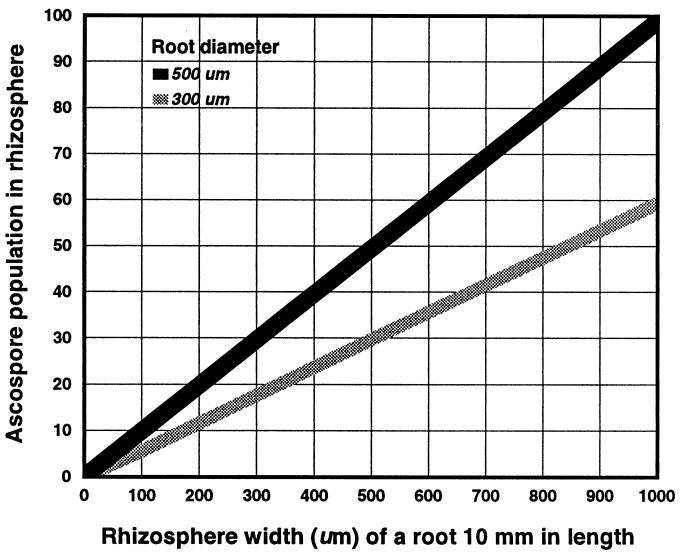

Fig. 8. Estimated ascospore population densities in rhizosphere soil adjacent to cantaloupe roots of known dimensions. 
The number of ascospore germlings attached to melon roots in control and streptomycin-amended soil were not statistically different. Preliminary studies showed that, in the absence of attachment, $\approx 9 \%$ of the ascospore population germinated. The latter observation was documented as follows: the soil washed from the roots systems of plants from various treatments that did not support high numbers of ascospores attached to the root system was passed through a $25-\mu \mathrm{m}$ sieve, and material retained on the sieve was backwashed into a petri dish. The number of germinated and nongerminated ascospores recovered from soil were enumerated microscopically.

Estimation of percentage of ascospore germination. As previously mentioned, the population density of the fungus in the artificially infested soil was 4,640 ascospores per $g$ of soil. The latter population densities were equivalent to 6.3 ascospores per $\mathrm{mm}^{3}$ of soil. Most of the secondary roots of 8-day-old seedlings ranged from 0.3 to $0.5 \mathrm{~mm}$ in diameter; therefore, the maximum population densities of the pathogen in various volumes of rhizosphere soil adjacent to root segments measuring $10 \mathrm{~mm}$ long and 0.3 and $0.5 \mathrm{~mm}$ in diameter was estimated (Fig. 8). The estimated number of ascospores per unit volume of rhizosphere soil then was compared to the observed number of ascospore germlings attached to roots after 8 days of incubation at $25^{\circ} \mathrm{C}$. Two secondary roots, measuring $10 \mathrm{~mm}$ long and $0.3 \mathrm{~mm}$ in diameter, and two roots measuring $10 \mathrm{~mm}$ long and $0.5 \mathrm{~mm}$ in diameter, were excised from the tap root and assessed as described above (Table 1).

\section{DISCUSSION}

As a general phenomenon, survival structures of soilborne fungal plant pathogens are under the influence of soil fungistasis and germination of these survival structures are induced directly by a component or components of host, as well as nonhost, root exudates $(4,7)$. There are, however, some exceptions, such as Sclerotium cepivorum. In soil, sclerotia of $S$. cepivorum are stimulated to germinate only in the rhizosphere of members of the genus Allium. Additionally, specific Allium spp. root exudates, (e.g., the water-soluble, nonvolatile allyl cysteine sulphoxides), are broken down by soil bacteria to give mixtures of volatile alkyl thiols and sulfides. These degradation products apparently function as the stimulus for germination of sclerotia in field soil (5).

Our studies indicate that bacterial mediation also appears to be involved in the stimulation of germination of ascospores of $M$. cannonballus in field soil. Significantly higher numbers of ascospore germlings were consistently observed on roots of melon seedlings growing in nonautoclaved compared with autoclaved field soil. Autoclaving presumably destroyed the resident soil microflora, indicating that (i) the soil microflora, either directly or indirectly, was involved in the induction of ascospore germination in field soil and (ii) root exudates alone do not provide the stimulus for ascospore germination. The involvement of the soil microflora in ascospore germination was further implicated by amending field soil with chemicals that selectively inhibit certain groups of microorganisms. Specifically, amending nonautoclaved field soil with streptomycin, which primarily inhibits the gram-negative bacteria, had no significant effect, relative to control soil, on the number of ascospore germlings attached to melon roots. However, amending soil with penicillin, which inhibits primarily gram-positive microorganisms, significantly decreased the number of ascospore germlings attached to melon roots compared to melon roots growing in control soil. Cumulatively, these results showed that the grampositive, but not the gram-negative, soil microorganisms were associated with ascospore germination. Gram-positive microorganisms include bacteria as well as the actinomycetes. Thus, we amended field soil with PCNB, a chemical that selectively (at concentrations of 100 to $200 \mu \mathrm{g} / \mathrm{ml}$ ) inhibits the gram-positive actinomycetes but not the gram-positive or -negative bacteria (2). Results showed that significant reductions in the numbers of ascospore germlings occurred on roots of melons growing in PCNB-amended soil compared with control soil. These latter results indicate that the actinomycetes, either directly or indirectly, are involved in the induction of ascospore germination in the rhizosphere of melon roots. Actinomycetes, via production of volatile metabolites, have previously been demonstrated to enhance germination of resting structures of a mycorrhizal fungus, Gigaspora margarita (1). Identification of the specific group of actinomycetes, as well as the specific chemicals, that are putatively associated with the induction of ascospore germination are currently under investigation.

In addition to the influence of the soil microflora on the induction of ascospore germination, high soil temperatures were also shown to significantly increase both the rate and the percentage of germination of ascospores in field soil. Maximum numbers of ascospores germinated between 7 and 8 days of incubation at $35^{\circ} \mathrm{C}$ (Fig. 1). Similar rates of germination and numbers of ascospore germlings attached to roots were recorded at $25^{\circ} \mathrm{C}$. No germination occurred at $15^{\circ} \mathrm{C}$. At $20^{\circ} \mathrm{C}$, the rate of germination was three times slower than at 25,30 , or $35^{\circ} \mathrm{C}$. While slow germination rates of survival structures of a few soilborne plant pathogenic fungi have been reported $(1,10)$, most survival structures (4) germinate within hours (i.e., 2 to $12 \mathrm{~h}$ ) after receiving a germination signal (i.e., root exudate). The slow rate of germination of ascospores, at optimum and suboptimum soil temperatures, may be related to the growth rate, or critical population density, of the actinomycete that appears to be involved in the production of specific metabolites that induce ascospore germination. Further, the optimum temperatures for ascospore germination coincided with those temperatures optimum for vegetative growth as reported here and previously (6).

Concerning the percentage of germination of a known soil population of ascospores, direct observation showed that there were $\approx 40$ ascospore germlings attached, via the germ tube, to roots measuring $10 \mathrm{~mm}$ long and $0.5 \mathrm{~mm}$ in diameter, and 21 ascospores attached to roots measuring $10 \mathrm{~mm}$ long and $0.3 \mathrm{~mm}$ in diameter. Additionally, we showed that the maximum length of germ tubes of ascospore germlings attached to the roots was $500 \mu \mathrm{m}$. Based upon the assumption that germ-tube growth occurred perpendicular to the growing root, $500 \mu \mathrm{m}$, thus, represents the maximum width of the rhizosphere effect (e.g., competency zone) (3). When the actual numbers of germlings attached to roots were compared to the expected population density per unit volume of soil within $500 \mu \mathrm{m}$ of a root of the same dimension (Fig. 8), the data indicate that not less than $72 \%$ of the estimated ascospore population are capable of germination and subsequent host penetration. Whether all penetrations resulted in successful host colonization (i.e., inoc-

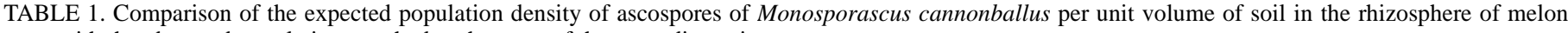
roots with the observed population attached to the roots of the same dimensions

\begin{tabular}{|c|c|c|c|c|c|c|}
\hline $\begin{array}{l}\text { Root length } \\
(\mathrm{mm})\end{array}$ & $\begin{array}{l}\text { Root diameter } \\
(\mathrm{mm})\end{array}$ & $\begin{array}{l}\text { Rhizosphere width } \\
\text { (mm) }\end{array}$ & $\begin{array}{l}\text { Rhizosphere volume } \\
\left(\mathrm{mm}^{3}\right)^{\mathrm{a}}\end{array}$ & $\begin{array}{c}\text { Expected } \\
\text { population }^{\mathrm{b}}\end{array}$ & $\begin{array}{c}\text { Observed } \\
\text { population }^{\mathrm{c}}\end{array}$ & $\begin{array}{l}\text { Percent expected } \\
\text { population }\end{array}$ \\
\hline 10 & 0.3 & 0.5 & 4.71 & 29.7 & $21.1 \pm 4.6$ & 72 \\
\hline 10 & 0.5 & 0.5 & 7.85 & 49.5 & $40.4 \pm 4.8$ & 81 \\
\hline
\end{tabular}

${ }^{a}$ Rhizosphere volume is the product of root length, root diameter, and rhizosphere width.

${ }^{b}$ Based on 6.3 ascospores pe $\mathrm{mm}^{3}$ of soil.

c Based on actual number of ascospore germlings attached to six roots of each of the above dimensions \pm standard error of mean. 
ulum efficiency) is not know at this time but is currently under investigation.

\section{LITERATURE CITED}

1. Carpenter-Boggs, L., Olynachan, T. E., and Stahl, P. D. 1995. Spore germination of Gigaspora margarita stimulated by volatiles of soil-isolated actinomycetes. Soil Biol. Biochem. 27:1445-1451.

2. Farley, J. D., and Lockwood, J. L. 1968. The suppression of actinomycetes by PCNB in culture media used for enumerating soil bacteria. Phytopathology 58:714-715.

3. Grogan, R. G., Sall, M. A., and Punja, Z. K. 1980. Concepts for modeling root infection by soilborne fungi. Phytopathology 70:361-363.

4. Huisman, O. C. 1982. Interrelations of root growth dynamics to epidemiology of root-invading fungi. Annu. Rev. Phytopathol. 20:303-327.

5. King, J. E., and Coley-Smith, J. R. 1969. Effects of volatile products of
Allium species and their extracts on germination of Sclerotium ceprivorum Berk. Ann. Appl. Bio. 64:303-314.

6. Martyn, R. D., and Miller, M. E. 1996. Monosporascus root rot and vine decline, an emerging disease of melons worldwide. Plant Dis. 80:716-725.

7. Schroth, M. N., and Hildebrand, D. C. 1964. Influence of plant root exudates on root-infecting fungi. Annu. Rev. Phytopathology 2:101-132.

8. Stanghellini, M. E., Kim, D. H., and Rasmussen, S. L. 1996. Ascospores of Monosporascus cannonballus: Germination and distribution in cultivated and desert soils in Arizona. Phytopathology 86:509-514.

9. Stanghellini, M. E., and Rasmussen, S. L. 1992. A quantitative method for the recovery of ascospores of Monosporascus cannonballus from field soil. (Abstr.) Phytopathology 82:1115.

10. Westerlund, F. V., Campbell, R. N., Grogan, R. G., and Duniway, J. M. 1978. Soil factors affecting the reproduction and survival of Olpidium brassicae and its transmission of big vein agent to lettuce. Phytopathology 68:927-935. 